\title{
Is Axillary Sentinel Lymph Node Biopsy Required in Patients Who Undergo Primary Breast Surgery?
}

\author{
Toralf Reimer $^{\mathrm{a}} \quad$ Jutta Engel $^{\mathrm{b}} \quad$ Marcus Schmidt $^{\mathrm{c}}$ Birgitte Vrou Offersen ${ }^{\mathrm{d}}$ Marjolein L. Smidt ${ }^{\mathrm{e}}$ \\ Oreste David Gentilini ${ }^{f}$ \\ ${ }^{a}$ Department of Obstetrics and Gynecology, University of Rostock, Rostock, Germany; \\ ${ }^{b}$ Munich Cancer Registry (MCR) of the Munich Tumour Centre, Institute of Medical Information Processing, Biometry and Epidemiology, \\ Ludwig Maximilians-University (LMU), Munich, Germany; \\ ${ }^{c}$ Division of Molecular Medicine, Department of Obstetrics and Gynecology, Comprehensive Cancer Center, \\ University Medical Center Mainz, Mainz, Germany; \\ dDepartment of Experimental Clinical Oncology and Department of Oncology, Aarhus University Hospital, Aarhus, Denmark; \\ e Division of Surgical Oncology, Maastricht University Medical Centre, Maastricht, Netherlands: \\ ${ }^{f}$ Breast Surgery Unit, San Raffaele University and Research Hospital, Milan, Italy
}

\section{Keywords}

Breast cancer - Axillary therapy .

Sentinel lymph node biopsy · Clinical trials

\section{Summary}

Local treatment of the axilla in clinically node-negative (cNO) early breast cancer patients with routine sentinel lymph node biopsy (SLNB) is debated for various reasons: i) $\mathrm{pN}$ staging information may not be necessary for the postoperative treatment decision regarding adjuvant systemic therapy in the great majority of patients; ii) the SLNB-positive rate is declining below $20 \%$ in specialized breast centers; iii) albeit being a minimally invasive procedure, SLNB causes a significant reduction in quality of life in $23 \%$ of patients; and iv) previous randomized trials from the pre-SLNB era did not show a disadvantage for patients without axillary surgery with regard to overall survival. These data support the hypothesis that avoiding axillary treatment in patients with clinically and sonographically unsuspicious lymph nodes seems to be a safe option, although omitting axillary surgery may increase the risk of locoregional recurrence. Currently, the information regarding node-positive status is essential to guide postoperative treatment such as systemic or radiation therapies in a non-negligible minority of patients. Three ongoing prospective European trials (SOUND, INSEMA, BOOG 2013-08) with axillary observation alone versus SLNB in cNO patients and primary breast-conserving surgery have the objective to evaluate oncologic safety when omitting SLNB.

(C) 2018 S. Karger GmbH, Freiburg

\section{From the View of the Epidemiologist}

\section{Jutta Engel}

The Munich Cancer Registry (MCR) is the population-based clinical cancer registry of Upper Bavaria and, partly, of Lower Bavaria (Southern Germany) [1]. Its epidemiologic catchment area currently comprises approximately 4.8 million inhabitants. Figure 1 shows trends in axillary lymph node dissection (ALND) and sentinel lymph node (SLN) biopsy (SLNB) over 15 years in the MCR for 43,435 patients with invasive breast cancer (M0 at diagnosis, without neoadjuvant therapy). According to this, more than $80 \%$ of this population-based collective received an SLNB, either exclusively (66.1\%) or followed by an ALND (15.5\%). Further, in women without clinical evidence of positive lymph nodes, SLNB is performed in over $85 \%$ [1].

\section{In Principle, SLNB Could Be Necessary for Two Reasons}

Firstly, SLNB could be needed as a diagnostic tool to support decisions regarding further adjuvant systemic therapy and predict response to therapy. However, this exclusive diagnostic function of the SLNB could be replaced by information from the primary tumor; the analysis of gene expression profiles has identified molecular (intrinsic) subtypes of breast cancer that differ significantly in their response to therapy [2-4]. Alternatively, a classification in which these subtypes are distinguished by an immunohistochemical algorithm is proposed as a surrogate [2]. Accordingly, the St. Gallen Consensus incorporated this biological model $[2,5,6]$.

Secondly, SLNB could be needed as a therapeutic procedure to identify affected lymph nodes and remove them (possibly with subsequent ALND), since it is a commonly held belief that a meta-

\section{KARGER}

() 2018 S. Karger GmbH, Freiburg

Fax +497614520714 
Fig. 1. Trends for axillary lymph node dissection (ALND) and sentinel lymph node biopsy (SLNB) over 15 years in the data of the Munich Cancer Registry for 43,435 patients with invasive breast cancer (M0 at diagnosis, without neoadjuvant therapy).

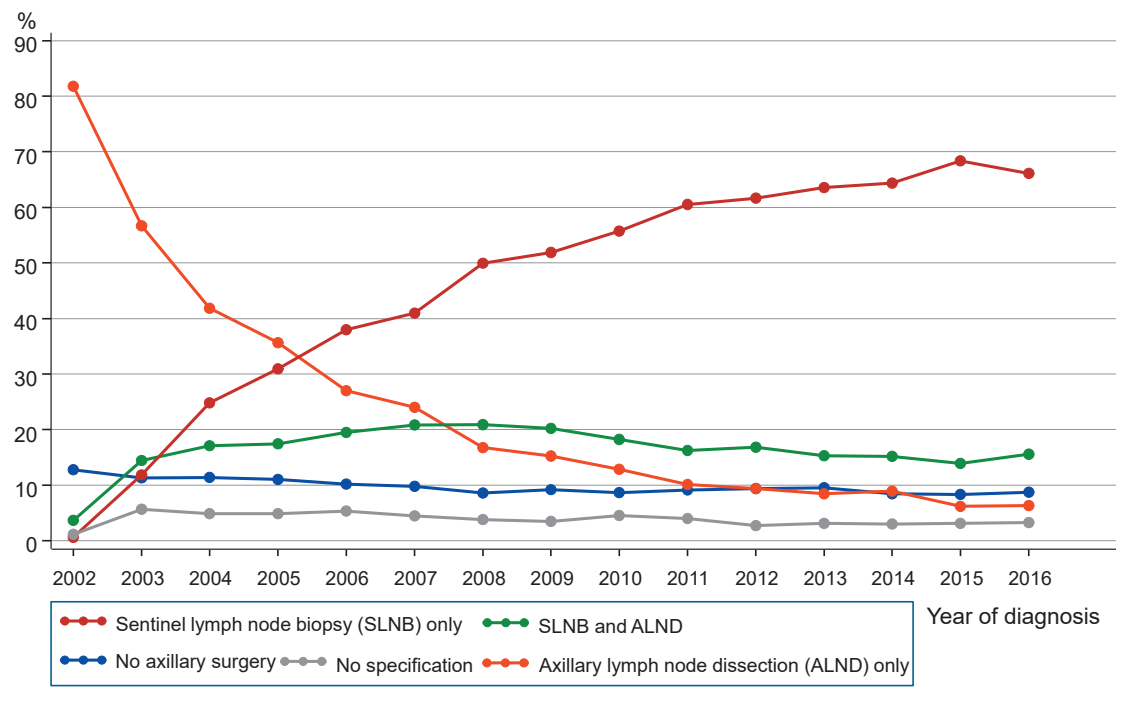

static risk could emanate from these affected lymph nodes. However, this therapeutic function of SLNB seems superfluous, because recent evidence demonstrates that no risk of metastasis emerges from positive lymph nodes [7].

Risk of metastasis arises from the primary tumor only (as long as it is not removed) which is amplified by the arguments below.

- The first argument is supported by evidence-based medicine. There are several randomized controlled trials (six for breast cancer only) in which ALND was omitted partly or completely. No single randomized study without regional lymph node removal showed any survival disadvantage [8-13]. An important question is whether this has to be proven repeatedly for each tumor or whether there is a common biologic principle.

- A second argument is provided by studies with neoadjuvant therapy, which show that the lymph node status is partly reversible, but no prognostic improvement is achieved [14].

- In addition, anatomy and physiology give no indication of a filter function of lymph nodes. Dissemination of tumor cells takes place from the primary tumor and propagates in parallel by both lymphogenous and hematogenous spread. The relationship between the two systems may be so intertwined that their separation, and therefore a cascade principle, is unrealistic [15-17].

- An independent argument provides a linear relationship between the diameter of the primary tumor, 10-year tumor-specific mortality, proportion of positive lymph node status, and number of positive lymph nodes. A non-linear relationship would be expected for a cascade principle, but the development shows a linear relationship. The regression line shows that with every millimeter-increase in tumor diameter, a further $1.2 \%$ of patients develop positive lymph nodes. That means, for large tumors, the SLN is the 'oldest' one, but not significantly larger than the 'youngest' lymph node itself. Thus, the primary tumor sequentially affects the lymph nodes, and there seems to be a growth limitation in the macroscopic sector [7].
- Relationships between tumor growth times, onset of metastasis, and death, as well as the long latency from the initiation of metastases to their diagnosis of about 7-8 years argue against a cascade theory and in favor of a parallel dissemination starting from the primary tumor [18].

- Meanwhile, there is also evidence from gene analyses that distant metastases arise from various clones of the primary tumor (and not from the lymph nodes). We know that a primary tumor will acquire gene mutations over time. Results of gene sequencing of various tumor foci of individual patients indicate that these gene mutations can be detected in the secondary foci, e.g., in two different liver foci or in patients with affected lymph nodes. Thus, both the chronologic order and the mutations of the primary tumor can be found in the metastases [19].

- A number of studies on gene analysis have shown that the site of metastasis can be seen in the gene signature of the primary tumor. For breast cancer, gene signatures were published in 2003 for bone metastatic colonization [20], in 2005 for the lung [21], and finally in 2009 for the central nervous system [22]. 'Metastatic potential' thus starts in the cells of the primary tumor, and these disseminated cells can then form metastases if the organ-specific properties match the gene signature they carry. The 'seed and soil' principle by Paget [23] seems to be valid.

- In the meantime, gene signatures are also determined by gene expression analyses, which allow a more accurate prognosis of survival in patients with both positive and negative lymph node status [24]. Gene expression analyses of the primary tumor enable a prognosis independent of the lymph node status, weakening the benefit provided by the knowledge of lymph node status.

- The metastatic process is based on comparable biologic capabilities acquired during the multistep development of human tumors. The hallmarks of cancer constitute an organizing principle for rationalizing the complexities of neoplastic disease [25]. Therefore, plenty of genes are required which the cells of the primary tumor must have (or numerous driver mutations 
which the primary tumor 'acquires' during growth $[25,26])$ to be able to successfully metastasize at all. Also, a pre-metastatic niche, which can be formed only from the primary tumor, seems to be necessary [27]. The process of metastasis is complex and starts from the primary tumor, not from positive lymph nodes [7, 28, 29].

In summary, from our point of view, SLNB is not required, neither as a diagnostic nor as a therapeutic intervention in routine care [30].

\section{Surgeon's View: Pros and Cons for SLNB}

\section{Oreste Gentilini, Toralf Reimer, Marjolein L. Smidt}

Previous randomized trials comparing ALND versus no axillary surgery in clinically node-negative patients ( $\mathrm{cN} 0$ ) showed no benefit regarding overall survival for the ALND arm, even with longterm follow-up [31]. Currently, SLNB is accepted as staging procedure in $\mathrm{cN} 0$ patients with a false-negative rate of $6-8 \%$ [32]. Historically, $\mathrm{pN}$ status as an important prognostic factor was an indicator for (neo-)adjuvant systemic treatment and postoperative radiotherapy (RT). Today, systemic treatment is planned mostly according to tumor biology like intrinsic tumor subtypes, tumor grade, and Ki-67 rather than nodal status. Chemotherapy and/or targeted therapy is always indicated for triple-negative and human epidermal growth factor receptor 2(HER2)-positive tumors (stage pT1b and above) independently of SLNB results. In luminal-like breast cancer, the indication for chemotherapy is more and more based on the use of multi-gene assays in patients with pN1a [33]. In conclusion, the only indication for a SLNB in cN0 patients who undergo primary surgery is to identify 4 or more involved axillary lymph nodes in luminal-like breast carcinomas resulting in a clear indication for postoperative chemotherapy and RT. In the AMAROS trial and a Dutch population-based study, only 3 and 1.7\%, respectively, of all luminal-like tumors in an SLNB cohort showed 4 or more involved axillary lymph nodes ( $\geq$ stage pN2a) $[34,35]$. Hence, even here, the chances of added value from the SLNB concerning treatment changes are low.

Initially in the NSABP B-32 trial, the SLN-positive rate was 29\% [36]. Currently, in the era of mammographic screening, the reported SLN-positive rates in highly specialized centers are below 20\%. A Memorial Sloan Kettering analysis revealed an SLN-positive rate of $17.6 \%$ in a breast-conserving surgery (BCS) cohort [37]. This finding is confirmed by a Mayo Clinic cohort in another unicentric evaluation of 1,140 patients (T1/T2) with an SLN-positive rate of $13 \%$ [38]. These cN0 patients were all preoperatively evaluated by axillary ultrasound (AUS) with or without fine-needle aspiration (FNA) biopsy.

As expected, postoperative morbidity (lymphedema, numbness or paresthesia, impairment of arm mobility) is significantly lower with SLNB compared to ALND [39]. However, SLNB is still an invasive staging procedure resulting in a significant reduction in quality of life in $23 \%$ of patients and lymphedema in over $8 \%$ of patients after only 3 years [40].
Omission of Axillary Surgery: Published Randomized Trials

Prior to the SLNB era, trials comparing ALND versus no axillary surgery and versus axillary RT were conducted to avoid the side effects of level I/II ALND [41]. 4 prospective trials randomized breast cancer patients to ALND versus no axillary surgery. These studies showed a low axillary recurrences rate, even in the no surgery arms, although nodal involvement in the ALND group ranged from 23 to $40 \%$. No significant differences between the study arms could be found for survival outcomes [12, 42-44]. However, the decreased diagnostic possibilities at the time of inclusion in the trials should be borne in mind. Clinical node positivity $(\mathrm{cN}+)$ was solely based on physical examination, since AUS \pm biopsy, positron emission tomography-computed tomography, and magnetic resonance imaging were not or less in use. Their arrival increased the percentage of $\mathrm{cN}+$ patients and allowed the selection of the $\mathrm{cN} 0$ group with a lower tumor burden.

Current guidelines define patients who can be saved from axillary surgery. NCCN guidelines define axillary staging as optional for patients with favorable tumors, with serious comorbid conditions, or with a certain indication for adjuvant systemic therapy [45]. The German AGO guidelines recommend avoiding axillary surgery in elderly patients ( $\geq 60$ years, cN0, hormone receptor-positive) with comorbidities and a life expectancy of less than 5 years [46].

Summarizing these data, avoiding axillary surgery in patients with clinically and sonographically unsuspicious lymph nodes seems to be a safe option, although it may slightly increase the risk of locoregional recurrence [31]. Further studies are needed to define subgroups of patients that do not profit from axillary staging and can be spared from its possible side effects.

\section{Ongoing Clinical Trials}

Three European trials were designed to compare SLNB versus observation when physical examination and AUS are negative in patients with BCS. The Italian SOUND, German/Austrian INSEMA (Intergroup Sentinel Mamma), and Dutch BOOG 2013-08 trials focus on this question with different inclusion criteria.

The SOUND trial is a prospective randomized multicentric study, designed by the European Institute of Oncology (EIO) of Milan. Eligibility and exclusion criteria were published by Gentilini and Veronesi [47, 48]. Briefly, cT1N0 patients treated with BCS underwent an AUS in order to rule out evident or suspicious nodal involvement. Patients with either negative AUS or negative FNA were randomized to 2 groups: SLNB (+ ALND mandatory in all cases with SLN macrometastases) versus no axillary surgery. The mandatory completion ALND is a critical point with respect to the ACOSOG Z0011 data [49]. The primary endpoint is distant disease-free survival (DDFS) with the assumption to obtain reliable results in a shorter period of time compared to overall survival. Overall, 1,560 women (780 per arm) were required to establish whether the observation group did not have worse outcome than the SLNB group, given a margin $\Delta$ of non-inferiority of $2.5 \%$ (maximum tolerable 5-year DDFS $=94 \%$ ) [47]. The first patient was included in January 2012; recruitment closed after 1,464 patients in June 2017. 
The goal of the ongoing German/Austrian INSEMA study is to show that a reduced extent of axillary surgery is not inferior with regard to invasive disease-free survival (IDFS) outcome compared to the standard arm in early-stage breast cancer patients. In this trial, patients with breast cancer $\leq 5 \mathrm{~cm}(\mathrm{~T} 1 / \mathrm{T} 2)$, node-negative axilla (clinically and/or per imaging), planned BCS, and age $\geq 18$ years can be recruited [50]. Patients will be first randomized to either no axillary surgery or SLNB in a 1:4 allocation. Patients with SLNB and $\mathrm{pN}+(\mathrm{sn})$ status will be secondly randomized (1:1 ratio) to either SLNB alone or completion ALND in the case of $<4$ involved nodes (1-3 macrometastases). Due to the unequal-sample-size design, the total number of patients amounts to 6,740. In addition to the SOUND trial, INSEMA aims to clarify certain problems of ACOSOG Z0011: distribution of axillary isodoses with standard wholebreast irradiation and ignoring of SLNB with micrometastases for second randomization. After first-patient-in on 17 September 2015, the current recruitment (March 2018) for the first randomization is concordant with the planned target ( $\mathrm{n}=3,930$ included).

The Dutch BOOG 2013-08 trial is a non-inferiority randomized controlled multicenter trial. Women with $\mathrm{cN} 0 \mathrm{~T} 1-2$ invasive breast cancer undergoing BCS will be randomized to SLNB versus no SLNB. In the case of SLNB and involved nodes, additional treatment is provided according to local guidelines. In contrast to SOUND and INSEMA, patients with neoadjuvant chemotherapy are included as well. The primary endpoint is the regional recurrence rate after 5 years; the estimated sample size is 1,644 patients [51]. The current status of recruitment is $n=506$ (March 2018).

\section{From the View of the Medical Oncologist}

\section{Marcus Schmidt}

From a medical oncologist's point of view, SLNB is required in patients who undergo primary surgery. For proper planning of adjuvant systemic therapies, knowing the nodal status of a patient is still of utmost importance, even in the era of a rapidly increasing understanding of tumor biology.

It is well accepted that anthracycline- and taxane-containing adjuvant chemotherapy reduces the risk of breast cancer mortality by approximately one-third [52]. It is evident that the proportional reduction in mortality depends on the level of risk of the individual patient. In order to avoid over- as well as under-treatment, it is advisable to select the appropriate treatment strategy on the basis of a careful risk assessment for each individual patient.

An important pathologic factor for risk stratification in primary breast cancer is the nodal status [53]. Moreover, Jatoi et al. [54] showed that nodal metastasis is not only a marker of diagnosis at a later point in the natural history of breast cancer but also a marker of an aggressive phenotype. Even in the era of a more thorough understanding of tumor biology in early breast cancer, nodal status remains an important prognostic factor. When developing a gene expression signature for estrogen receptor(ER)-positive/HER2negative early breast cancer, we realized that the prognostic accuracy could be substantially improved after including the number of involved lymph nodes in the model [55]. The molecular information of EndoPredict ${ }^{\circledR}$ (EP) (Myriad Genetics, Salt Lake City, UT, USA) was consequently combined with the clinical parameters nodal status and tumor size, resulting in the molecular and clinical risk score, EndoPredict-clin (EPclin) which outperformed all conventional clinicopathologic risk factors in prospective-retrospective validation studies [56]. It is evident that nodal status is a strong prognostic factor regardless of gene expression signature [6]. This again emphasizes the relevance of established clinicopathologic factors like nodal status for a comprehensive and reliable assessment of the risk of recurrence for an individual patient. Indeed, node-positive status is a well-established prognostic factor arguing for adjuvant chemotherapy [6].

Especially in node-negative breast cancer, risk assessment with conventional clinicopathologic factors is not always sufficient to guide chemotherapy. Gene expression signatures might be used in selected ER-positive/HER2-negative patients [6]. In any case, this implies that knowledge of the nodal status is of paramount importance when selecting the most appropriate systemic therapy for a given patients.

Concerning patients with HER2-positive early breast cancer, nodal status is important to select the chemotherapy backbone. Node-negative patients with HER2-positive breast cancer measuring up to $3 \mathrm{~cm}$ in greatest dimension fare very well when trastuzumab is combined with weekly paclitaxel [57]. Furthermore, nodal status is important when deciding which HER2-positive patient benefits from dual antibody blockade with trastuzumab and pertuzumab. In the recently published APHINITY study, only node-positive but not node-negative patients had improved IDFS with the addition of pertuzumab to trastuzumab and chemotherapy [58].

Even when considering the duration of adjuvant endocrine therapy in hormone receptor-positive breast cancer patients, nodal status plays an important role. Current consensus recommendations approve an extended endocrine therapy for patients with intermediate/high 'clinical risk' (node-positive) [6].

In conclusion, knowing the lymph node status is important when selecting the most appropriate systemic therapy. Omitting assessment of axillary lymph nodes would lead to less individualized treatment decisions. Because of this, SLNB is required in patients who undergo primary surgery.

\section{The Radiation Therapy Perspective}

\section{Birgitte Vrou Offersen}

The status of the axilla in early breast cancer patients is of utmost importance because it is a strong prognostic factor and guides optimal locoregional and systemic therapy. From an RT perspective, there are essentially 2 types of radiation treatment planning: local RT and locoregional RT. Local RT involves irradiation of only the residual breast after BCS, and it can be whole breast or partial breast treatment planning. Locoregional RT includes irradiation of the breast/chest wall and regional nodes, including all or selected levels I-IV, the Rötter nodes, and the internal mammary nodes $[59,60]$. 
In many countries, the shift from local RT to locoregional RT occurs when one macrometastasis is present in the axilla, and since locoregional RT per se causes more dose to heart and lungs and thereby increases the risk of serious late effects, it is very important to know for sure if a macrometastasis is present [61-64]. Highly specialized centers report positive SLNB in less than $20 \%$ of their patients; however, a nationwide evaluation of SLNB between 2010 and 2015 by the Danish Breast Cancer Group (DBCG) revealed macrometastases (not just positive nodes) in $21 \%$ of all SLNB, and in the group with sentinel macrometastases, $14 \%$ had pN2 disease and 6\% had pN3 disease at ALND [37, 64]. Preoperative ultrasound was performed as part of the DBCG guideline. These findings strongly indicate that evaluating the status of the axilla with palpation and ultrasound is difficult, and that SLNB adds valuable information for the optimal selection of adjuvant treatment.

Virtually all developed countries recommend locoregional RT if pN2-3 disease is present, so if SLNBs are abandoned, patients with cN0pN2-3 disease are recommended neither potentially life-saving chemotherapy nor locoregional RT. Based on the results from the above-mentioned DBCG retrospective study, the likelihood of having cN0pN2-3 disease is low (approximately 4\%); however, the consequences of not being offered evidence-based treatment may be serious for these patients. It is also very likely that the statistic power of trials testing omission of SLNB is too low to detect this problem. The trials testing omission of SLNB (SOUND, INSEMA, and BOOG 2013-08) all have 5-year endpoints (DDFS, IDFS, and regional recurrence, respectively). Hopefully, these trials will recruit their planned number of patients, and results from nearly 10,000 patients will then be able to guide future directions. It will be paramount to follow the results from these trials also at 10 years and more.

When reporting outcome after SLNB only or after no SLNB, it is absolutely necessary to report RT-related technical information also. After results were reported from the ACOSOG Z0011 trial, it became clear that there had been virtually no control during the trial on details of the RT, so it was stated that 'high tangents' after BCS were recommended [65]. Using modern RT techniques based on meticulous target volume delineation followed by conformal radiation treatment planning to ensure optimal dose homogeneity and as low a dose as possible to organs at risk, 'high tangents' are not an option $[59,60]$. In women who have been influenced by gravity for many years, there may be several centimeters from the caudal edge of the humeral head to the cranial edge of the clinical target volume of the residual breast, thus radiation dose to level I is often very modest if the patient is not having locoregional RT. If the target for RT is not defined and delineated, it will not be adequately treated.

In the next 5-10 years, the surgical and radiation treatments of the axilla will be further refined based on new evidence currently collected in several trials. Until results from those trials are available, SLNB remains of pivotal importance in $\mathrm{cN} 0$ early breast cancer patients to inform optimal adjuvant locoregional and systemic therapy.

\section{Conclusion}

Currently, axillary surgery for breast cancer is a staging procedure that does not seem to influence breast cancer mortality, since the risk of developing metastasis depends mainly on the biologic behavior of the primary tumor (seed-and-soil model) [30]. Postsurgical therapy should therefore be based on biologic tumor characteristics rather than nodal involvement. However, some recommendations are still influenced by nodal status: the indication for regional node irradiation in $\geq \mathrm{pN} 2 \mathrm{a}$ disease, the decision of adding chemotherapy to endocrine treatment, the choice of chemotherapy regimen, the type and duration of endocrine treatment, or the adjuvant indication for dual anti-HER2 therapy. At the moment, it is still unclear what level of information is needed to properly treat our patients. The ongoing trials will hopefully help us to understand whether we might take the best decisions without the pathologic evaluation of nodal status. Improved staging power of imaging modalities is further desired in light of the low sensitivity of AUS.

SOUND, INSEMA, and BOOG cannot provide all the answers; for example, it remains unclear whether patients without SLNB can be offered partial breast irradiation alone in low-risk situations (allowed option in SOUND) and whether SLNB can also be avoided in patients with stage T1-2 tumors who have a mastectomy indication.

\section{Disclosure Statement}

We declare that there are no conflicts of interest related to this review

\section{References}

1 Munich Cancer Registry: Catchment area and cancer statistics. 2018. www.tumorregister-muenchen.de/en/ index.php.

2 Leitlinienprogramm Onkologie (Deutsche Krebsgesellschaft, Deutsche Krebshilfe, AWMF): S3-Leitlinie Früherkennung, Diagnose, Therapie und Nachsorge des Mammakarzinoms, Version 4.0, 2017, AWMF Registernummer: 032-045ol. www.leitlinienprogramm-onkologie.de/leitlinien/mammakarzinom/.
Perou CM, Sorlie T, Eisen MB, van de Rijn M, Jeffrey SS, Rees CA, Pollack JR, Ross DT, Johnsen H, Akslen LA, Fluge O, Pergamenschikov A, Williams C, Zhu SX, Lonning PE, Borresen-Dale AL, Brown PO, Botstein D: Molecular portraits of human breast tumours. Nature 2000;406:747-752.
Sorlie T, Perou CM, Tibshirani R, Aas T, Geisler S, Johnsen H, Hastie T, Eisen MB, van de Rijn M, Jeffrey SS, Thorsen T, Quist H, Matese JC, Brown PO, Botstein D, Lonning PE, Borresen-Dale AL: Gene expression patterns of breast carcinomas distinguish tumor subclasses with clinical implications. Proc Natl Acad Sci U S A 2001;98:10869-10874. 
5 Coates AS, Winer EP, Goldhirsch A, Gelber RD, Gnant M, Piccart-Gebhart M, Thurlimann B, Senn HJ: Tailoring therapies-improving the management of early breast cancer: St. Gallen international expert consensus on the primary therapy of early breast cancer 2015 . Ann Oncol 2015;26:1533-1546.

6 Curigliano G, Burstein HJ, Winer EP, Gnant M, Dubsky P, Loibl S, Colleoni M, Regan MM, Piccart-Gebhart M, Senn HJ, Thurlimann B; St. Gallen International Expert Consensus on the Primary Therapy of Early Breast Cancer 2017, Andre F, Baselga J, Bergh J, et al: De-escalating and escalating treatments for earlystage breast cancer: the St. Gallen international expert consensus conference on the primary therapy of early breast cancer 2017. Ann Oncol 2017;28:1700-1712.

7 Engel J, Emeny RT, Hölzel D: Positive lymph nodes do not metastasize. Cancer Metastasis Rev 2012;31:235-246.

8 Veronesi U, Marubini E, Mariani L, Valagussa P, Zucali R: The dissection of internal mammary nodes does not improve the survival of breast cancer patients. 30year results of a randomised trial. Eur J Cancer 1999; 35:1320-1325.

-9 Fisher B, Anderson S, Bryant J, Margolese RG, Deutsch M, Fisher ER, Jeong JH, Wolmark N: Twenty-year follow-up of a randomized trial comparing total mastectomy, lumpectomy, and lumpectomy plus irradiation for the treatment of invasive breast cancer. N Engl J Med 2002;347:1233-1241.

10 Veronesi U, Orecchia R, Zurrida S, et al: Avoiding axillary dissection in breast cancer surgery: a randomized trial to assess the role of axillary radiotherapy. Ann Oncol 2005; 16:383-388.

11 Martelli G, Boracchi P, De Palo M, Pilotti S, Oriana S, Zucali R, Daidone MG, De Palo G: A randomized trial comparing axillary dissection to no axillary dissection in older patients with T1N0 breast cancer: results after 5 years of follow-up. Ann Surg 2005;242:1-6; discussion 7-9.

12 Rudenstam CM, Zahrieh D, Forbes JF, Crivellari D, Holmberg SB, Rey P, Dent D, Campbell I, Bernhard J, Price KN, Castiglione-Gertsch M, Goldhirsch A, Gelber RD, Coates AS: Randomized trial comparing axillary clearance versus no axillary clearance in older patients with breast cancer: first results of international breast cancer study group trial 10-93. J Clin Oncol 2006;24:337-344.

13 Giuliano AE, Ballman KV, McCall L, Beitsch PD, Brennan MB, Kelemen PR, Ollila DW, Hansen NM, Whitworth PW, Blumencranz PW, Leitch AM, Saha S, Hunt KK, Morrow M: Effect of axillary dissection vs no axillary dissection on 10-year overall survival among women with invasive breast cancer and sentinel node metastasis: the ACOSOG Z0011 (Alliance) randomized clinical trial. JAMA 2017;318:918-926.

14 Fisher B, Bryant J, Wolmark N, Mamounas E, Brown A, Fisher ER, Wickerham DL, Begovic M, DeCillis A, Robidoux A, Margolese RG, Cruz AB Jr, Hoehn JL, Lees AW, Dimitrov NV, Bear HD: Effect of preoperative chemotherapy on the outcome of women with operable breast cancer. J Clin Oncol 1998;16:2672-2685.

15 Földi M, Földi E, Kubrik S: Lehrbuch der Lymphologie. München, Elsevier, Urban \& Fischer, 2010.

$\checkmark 16$ Fisher B, Fisher ER: Transmigration of lymph nodes by tumor cells. Science 1966;152:1397-1398.

17 Fisher B, Fisher ER: The interrelationship of hematogenous and lymphatic tumor cell dissemination: an experimental study. Rev Inst Nac Cancerol (Mex) 1966; 19:576-581.

18 Engel J, Eckel R, Kerr J, Schmidt M, Furstenberger G, Richter R, Sauer H, Senn HJ, Hölzel D: The process of metastasisation for breast cancer. Eur J Cancer 2003; 39:1794-1806.
19 Yachida S, Jones S, Bozic I, Antal T, Leary R, Fu B, Kamiyama M, Hruban RH, Eshleman JR, Nowak MA, Velculescu VE, Kinzler KW, Vogelstein B, IacobuzioDonahue CA: Distant metastasis occurs late during the genetic evolution of pancreatic cancer. Nature 2010; 467:1114-1117.

20 Kang Y, Siegel PM, Shu W, Drobnjak M, Kakonen SM, Cordon-Cardo C, Guise TA, Massague J: A multigenic program mediating breast cancer metastasis to bone. Cancer Cell 2003;3:537-549.

21 Minn A, Gupta G, Siegel P, Bos P, Shu W, Giri D, Viale A, Olshen A, Gerald W, Massague J: Genes that mediate breast cancer metastasis to lung. Nature 2005;436: 518-524.

22 Bos PD, Zhang XH, Nadal C, Shu W, Gomis RR, Nguyen DX, Minn AJ, van de Vijver MJ, Gerald WL, Foekens JA, Massague J: Genes that mediate breast cancer metastasis to the brain. Nature 2009;459:1005-1009.

23 Paget S: The distribution of secondary growths in cancer of the breast. Lancet 1889;133:571-573.

24 Van de Vijver MJ, He YD, van't Veer LJ, et al: A geneexpression signature as a predictor of survival in breast cancer. N Engl J Med 2002;347:1999-2009.

25 Hanahan D, Weinberg RA: Hallmarks of cancer: the next generation. Cell 2011;144:646-674.

26 Valastyan S, Weinberg RA: Tumor metastasis: molecular insights and evolving paradigms. Cell 2011;147: 275-292.

27 Sleeman JP: The lymph node pre-metastatic niche. J Mol Med (Berl) 2015;93:1173-1184.

28 Lambert AW, Pattabiraman DR, Weinberg RA: Emerging biological principles of metastasis. Cell 2017; 168:670-691.

29 Ullah I, Karthik GM, Alkodsi A, Kjallquist U, Stalhammar G, Lovrot J, Martinez NF, Lagergren J, Hautaniemi S, Hartman J, Bergh J: Evolutionary history of metastatic breast cancer reveals minimal seeding from axillary lymph nodes. J Clin Invest 2018;128:1355-1370.

30 Engel J, Lebeau A, Sauer H, Hölzel D: Are we wasting our time with the sentinel technique? Fifteen reasons to stop axilla dissection. Breast 2006;15:452-455.

31 Bromhan N, Schmidt-Hansen M, Astin M, Hasler E, Reed MW: Axillary treatment for operable primary breast cancer. Cochrane Database Syst Rev 2017;1: CD004561.

-32 Lyman GH, Giuliano AE, Sommerfield MR, Benson AB 3rd, Bodurka DC, Burstein HJ, Cochran AJ, Cody HS 3rd, Edge SB, Galper S, Hayman JA, Kim TY, Perkins CL, Podoloff DA, Sivasubramaniam VH, Turner RR, Wahl R, Weaver DL, Wolff AC, Winer EP: American Society of Clinical Oncology guideline recommendations for sentinel lymph node biopsy in early-stage breast cancer. J Clin Oncol 2005;23:7703-7720.

33 Krop I, Ismaila N, Andre F, Bast RC, Barlow W, Collyar DE, Hammond ME, Kuderer NM, Liu MC, Mennel RG, Van Poznak C, Wolff AC, Stearns V: Use of biomarkers to guide decisions on adjuvant systemic therapy for women with early-stage invasive breast cancer: American Society of Clinical Oncology clinical practice guideline focused update. J Clin Oncol 2017; 35:2838-2847.

-34 Straver ME, Meijnen P, van Tienhoven G, van de Velde CJH, Mansel RE, Bogaerts J, Demonty G, Duez N, Cataliotti L, Klinkenbijl J, Westenberg HA, van der Mijle H, Hurkmans C, Rutgers E: Role of axillary clearance after a tumor-positive sentinel node in the administration of adjuvant therapy in early breast cancer. J Clin Oncol 2010;28:731-737.

35 Duijsens G, Van Roozendaal LM, Schipper R-J, Paiman E, Siesling S, Pijnappel R, Lobbes M, Smidt ML: Minor risk for extensive lymph node metastases after a negative axillary ultrasound in breast cancer patients in the Netherlands. NTVO 2014;11:268-273.
6 Krag DN, Anderson SJ, Julian TB, Brown AM, Harlow SP, Costantino JP, Ashikaga T, Weaver DL, Mamounas EP, Jalovec LM, Frazier TG, Noyes RD, Robidoux A, Scarth HM, Wolmark N: Sentinel-lymph-node resection compared with conventional axillary-lymphnode dissection in clinically node-negative patients with breast cancer: overall survival findings from the NSABP B-32 randomised phase 3 trial. Lancet Oncol 2010;11:927-933.

-37 Dengel LT, Van Zee KJ, King TA, Stempel M, Cody HS, El-Tamer M, Gemignani ML, Sclafani LM, Sacchini VS, Heerdt AS, Plitas G, Junqueira M, Capko D, Patil S, Morrow M: Axillary dissection can be avoided in the majority of clinically node-negative patients undergoing breastconserving therapy. Ann Surg Oncol 2014;21:22-27.

38 Ibrahim-Zada I, Grant CS, Glazebrook KN, Boughey JC: Preoperative axillary ultrasound in breast cancer: safely avoiding frozen section of sentinel lymph nodes in breast-conserving surgery. J Am Coll Surg 2013;217: 7-15

39 Wang Z, Wu LC, Chen JQ: Sentinel lymph node biopsy compared with axillary lymph node dissection in early breast cancer: a meta-analysis. Breast Cancer Res Treat 2011;129:675-689.

40 Rao R, Euhus D, Mayo HG, Balch C: Axillary node interventions in breast cancer: a systematic review. JAMA 2013;310:1385-1394.

41 Reimer T, Hartmann S, Stachs A, Gerber B: Local treatment of the axilla in early breast cancer: concepts from the national surgical adjuvant breast and bowel project B-04 to the planned intergroup sentinel mamma trial. Breast Care 2014;9:87-95.

42 Fisher B, Jeong JH, Anderson S, Bryant J, Fisher ER, Wolmark N: Twenty-five-year follow-up of a randomized trial comparing radical mastectomy, total mastectomy, and total mastectomy followed by irradiation. N Engl J Med 2002;347:567-575.

43 Agresti R, Martelli G, Sandri M, Tagliabue E, Carcangiu ML, Maugeri I, Pellitteri C, Ferraris C, Capri G, Moliterni A, Bianchi G, Mariani G, Trecate G, Lozza L, Langer M, Rampa M, Gennaro M, Greco M, Menard S, Pierotti MA: Axillary lymph node dissection versus no dissection in patients with T1N0 breast cancer: a randomized clinical trial (INT09/98). Cancer 2014;120:885-893.

44 Martelli G, Boracchi P, Ardoino I, Lozza L, Bohm S, Vetrella G, Agresti R: Axillary dissection versus no axillary dissection in older patients with T1N0 breast cancer: 15-year results of a randomized controlled trial. Ann Surg 2012;256:920-924.

45 Gradishar, WJ, Anderson BO, Aft R, et al: NCCN Clinical Practice Guidelines in Oncology (NCCN guidelines) Breast Cancer, version 1.2018. www.nccn.org.

46 Members of the German AGO Breast Committee: Diagnosis and treatment of patients with primary and metastatic breast cancer. Guidelines of the AGO breast committee 2018. www.ago-online.de.

47 Gentilini O, Veronesi U: Abandoning sentinel lymph node biopsy in early breast cancer? A new trial in progress at the European Institute of Oncology of Milan (SOUND: Sentinel node vs Observation after axillary UltraSouND). Breast 2012;21:678-681.

48 Gentilini O, Veronesi U: Staging the axilla in early breast cancer: will imaging replace surgery? JAMA Oncol 2015;1:1031-1032.

49 Giuliano AE, McCall L, Beitsch P, Whitworth PW, Blumencranz P, Leitch AM, Saha S, Hunt KK, Morrow $\mathrm{M}$, Ballman K: Locoregional recurrence after sentinel lymph node dissection with or without axillary dissection in patients with sentinel lymph node metastases. Ann Surg 2010;252:426-433. 
50 Reimer T, Stachs A, Nekljudova V, Loibl S, Hartmann S, Wolter K, Hildebrandt G, Gerber B: Restricted axillary staging in clinically and sonographically node-negative early invasive breast cancer (c/iT1-2) in the context of breast conserving therapy: first results following commencement of the Intergroup-Sentinel-Mamma (IN SEMA) trial. Geburtsh Frauenheilk 2017;77:149-157.

51 Van Roozendaal LM, Vane MLG, van Dalen T, van der Hage JA, Strobbe LJA, Boersma LJ, Linn SC, Lobbes MBI, Poortmans PMP, Tjan-Heijnen VCG, van de Vijver KKBT, de Vries J, Westenberg AH, Kessels AGH, de Wilt JHW, Smidt ML: Clinically node negative breast cancer patients undergoing breast conserving therapy, sentinel lymph node procedure versus followup: a Dutch randomized controlled multicentre trial (BOOG 2013-08). BMC Cancer 2017;17:459.

52 Peto R, Davies C, Godwin J, Gray R, Pan HC, Clarke M, Cutter D, Darby S, McGale P, Taylor C, Wang YC, Bergh J, Di Leo A, Albain K, Swain S, Piccart M, Pritchard K: Comparisons between different polychemotherapy regimens for early breast cancer: metaanalyses of long-term outcome among 100,000 women in 123 randomised trials. Lancet 2012;379:432-444.

53 Fisher B, Bauer M, Wickerham DL, Redmond CK, Fisher ER, Cruz AB, Foster R, Gardner B, Lerner H, Margolese R: Relation of number of positive axillary nodes to the prognosis of patients with primary breast cancer. An NSABP update. Cancer 1983;52:1551-1557.

54 Jatoi I, Hilsenbeck SG, Clark GM, Osborne CK: Significance of axillary lymph node metastasis in primary breast cancer. J Clin Oncol 1999;17:2334-2340.

55 Brase JC, Kronenwett R, Petry C, Denkert C, Schmidt M: From high-throughput microarray-based screening to clinical application: the development of a second generation multigene test for breast cancer prognosis. Microarrays (Basel) 2013;2:243-264.
56 Filipits M, Rudas M, Jakesz R, et al: A new molecular predictor of distant recurrence in ER-positive, HER2negative breast cancer adds independent information to conventional clinical risk factors. Clin Cancer Res 2011;17:6012-6020.

57 Tolaney SM, Barry WT, Dang CT, Yardley DA, Moy B, Marcom PK, Albain KS, Rugo HS, Ellis M, Shapira I, Wolff AC, Carey LA, Overmoyer BA, Partridge AH, Guo H, Hudis CA, Krop IE, Burstein HJ, Winer EP: Adjuvant paclitaxel and trastuzumab for node-negative, HER2-positive breast cancer. N Engl J Med 2015; 372:134-141.

58 Von Minckwitz G, Procter M, de Azambuja E, Zardavas D, Benyunes M, Viale G, Suter T, Arahmani A, Rouchet N, Clark E, Knott A, Lang I, Levy C, Yardley DA, Bines J, Gelber RD, Piccart M, Baselga J: Adjuvant pertuzumab and trastuzumab in early HER2-positive breast cancer. N Engl J Med 2017;377:122-131.

59 Offersen BV, Boersma LJ, Kirkove C, Hol S, Aznar MC, Sola AB, Kirova YM, Pignol JP, Remouchamps V, Verhoeven K, Weltens C, Arenas M, Gabrys D, Kopek N, Krause M, Lundstedt D, Marinko T, Montero A, Yarnold J, Poortmans P: ESTRO consensus guideline on target volume delineation for elective radiation therapy of early stage breast cancer, version 1.1. Radiother Oncol 2016;118:205-208.

60 Offersen BV, Boersma LJ, Kirkove C, Hol S, Aznar MC, Biete Sola A, Kirova YM, Pignol JP, Remouchamps V, Verhoeven K, Weltens C, Arenas M, Gabrys D, Kopek N, Krause M, Lundstedt D, Marinko T, Montero A, Yarnold J, Poortmans P: ESTRO consensus guideline on target volume delineation for elective radiation therapy of early stage breast cancer. Radiother Oncol 2015;114:3-10.
EBCTCG (Early Breast Cancer Trialists' Collaborative Group); McGale P, Taylor C, Correa C, Cutter D, Duane F, Ewertz M, Gray R, Mannu G, Peto R, Whelan T, Wang Y, Wang Z, Darby S: Effect of radiotherapy after mastectomy and axillary surgery on 10-year recurrence and 20-year breast cancer mortality: metaanalysis of individual patient data for 8135 women in 22 randomised trials. Lancet 2014;383:2127-2135.

62 Grantzau T, Overgaard J: Risk of second non-breast cancer among patients treated with and without postoperative radiotherapy for primary breast cancer: a systematic review and meta-analysis of populationbased studies including 522,739 patients. Radiother Oncol 2016;121:402-413.

63 Darby SC, Ewertz M, McGale P, Bennet AM, BlomGoldman U, Brønnum D, Correa C, Cutter D, Gagliardi G, Gigante B, Jensen MB, Nisbet A, Peto R, Rahimi K, Taylor C, Hall P: Risk of ischemic heart disease in women after radiotherapy for breast cancer. $\mathrm{N}$ Engl J Med 2013;368:987-998.

64 Jessing C, Langhans L, Jensen MB, Talman ML, Tvedskov TF, Kroman N: Axillary lymph node dissection in breast cancer patients after sentinel node biopsy. Acta Oncol 2018;57:166-169.

65 Giuliano AE, Hunt KK, Ballman KV, Beitsch PD, Whitworth PW, Blumencranz PW, Leitch AM, Saha S, McCall LM, Morrow M: Axillary dissection vs no axillary dissection in women with invasive breast cancer and sentinel node metastasis: a randomized clinical trial. JAMA 2011;305:569-575. 